\title{
Dentigerous Cyst Associated with Mandibular 2nd Molar: An Unusual Entity
}

\author{
Govind Jindal $\cdot$ Hemant Batra $\cdot$ Supreet Kaur $\cdot$ \\ Deepti Vashist
}

Received: 11 August 2009/Accepted: 13 April 2010/Published online: 9 November 2012

(C) Association of Oral and Maxillofacial Surgeons of India 2012

\begin{abstract}
Dentigerous cysts are generally associated with the crowns of impacted or unerupted permanent teeth and are more common in males, in the second and third decades of life. Most dentigerous cysts are mainly developmental in origin but may not be similar for all cases. The purpose of this paper is to present a case of dentigerous cyst with unusual presentation in a 7 year old girl and discuss the variation in etiology, presentation of such a cyst and in its management.
\end{abstract}

Keywords Dentigerous cyst · Enucleation ·

Marsupialization

\section{Introduction}

Dentigerous cyst is defined as a cyst that originates by separation of the follicle from around the crown of unerupted tooth [1]. They are generally associated with the crowns of impacted or unerupted permanent teeth, but they can be associated with an odontoma or developing tooth [2], and even deciduous teeth [3,4].

It is the second most common type of odontogenic cysts, accounting for $49 \%$ of all cystic lesions [5]. Posterior mandible is by far the most commonly affected region [6].

Commonly affected teeth in order of frequency are, mandibular third molars, permanent maxillary canine, permanent maxillary third molar and less commonly permanent central incisor [2].

G. Jindal $(\bowtie) \cdot$ H. Batra $\cdot$ S. Kaur · D. Vashist BRS Dental College and Hospital, Sultanpur, India e-mail: docgovind@yahoo.co.in
Dentigerous cysts are more common in male patients [7] and frequently occur during the second and third decade of life $[1,8,9]$.

Most dentigerous cysts are mainly developmental [2] in origin, but few may have an inflammatory pathogenesis [1].

Patients with dentigerous cysts are mostly asymptomatic in early stages and have no painful symptoms unless there is an acute inflammatory exacerbation, thus explaining the fact that these lesions are often detected only during routine radiographic examination [10]. If the cyst reaches a large size ( $>2 \mathrm{~cm}$ in diameter), swelling, mild sensitivity, tooth mobility, and displacement may be observed [11].

Dentigerous cyst if infected, may become associated with pain and swelling. Such an infection may arise with a partially erupted tooth or by extention from a periapical or periodontal lesion that affects an adjacent tooth [1].

The radiographic pattern is characterized by a welldefined, unilocular radiolucent lesion surrounding the crown of an unerupted tooth. Cyst to crown relationship shows several variations: central, lateral and circumferential variants [1].

Other odontogenic cysts, such as radicular cyst and odontogenic keratocyst as well as odontogenic tumor such as ameloblastoma, calcifying epithelial odontogenic tumor and odontogenic fibroma might present characteristics similar to those of dentigerous cyst. Therefore histopathologic evaluation is necessary [12].

Histologically, dentigerous cysts consist of a fibrous wall containing variable amounts of myxoid tissue and odontogenic remnants. The cyst is lined with nonkeratinized stratified squamous epithelium consisting of mucosebaceous, ciliated and, rarely, sebaceous cells. The epithelial-connective tissue interface is typically flattened, but becomes highly irregular when associated with inflammation. 
The purpose of this paper is to present a case of dentigerous cyst with unusual presentation in a paediatric patient and discuss its management.

\section{Case Report}

A 7 year old girl presented to the Department of oral and maxillofacial surgery with a 1 month history of intraoral discharge and painless swelling located posteriorly on the right mandibular body which was gradually increasing in size. On extraoral examination, there was no obvious swelling of right side of mandible (Fig. 1). Intraorally there was expansion of the buccal cortex on the right posterior mandible leading to partial obliteration of right posterior buccal vestibule (Fig. 2). Overlying mucosa was normal in color and texture. Dental examination revealed, normal early mixed dentition with non carious deciduous molars and permanent first molar, on the affected side.

Upon palpation, the swelling was firm with certain areas of fluctuation. Also, compression of the swelling produced fluid discharge from the gingival sulcus opposite permanent first molar. Right submandibular lymph node was enlarged, tender, smooth and mobile.

On careful examination of the orthopantomogram, it was apparent that follicular space with respect to unerupted 47 tooth bud had increased by $2 \mathrm{~mm}$ when compared to the contralateral side (Figs. 3, 4). Needle aspiration revealed blood tinged fluid aspirate. The diagnosis of dentigerous cyst was made on clinical and radiographic presentation.

Preoperatively routine hematological, urine investigations and X-ray chest were performed. Mantoux test also showed

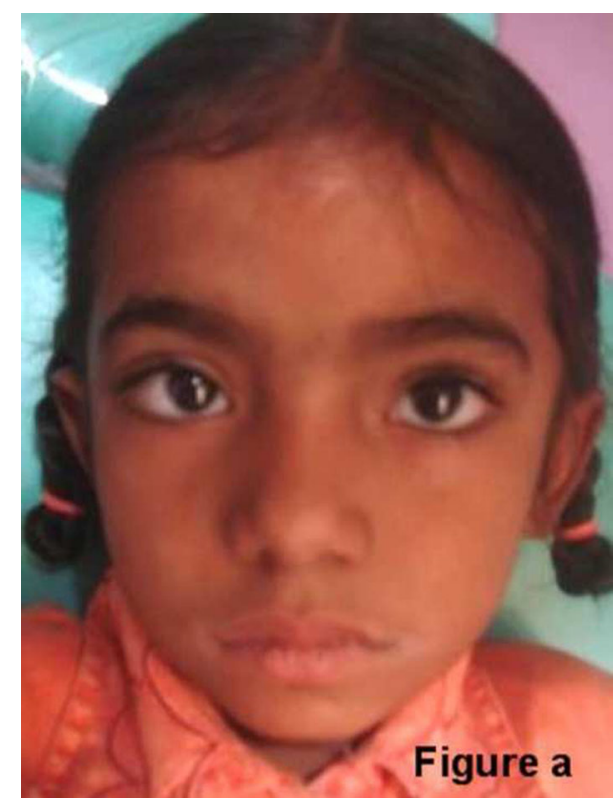

Fig. 1 Preoperative Extraoral Photograph

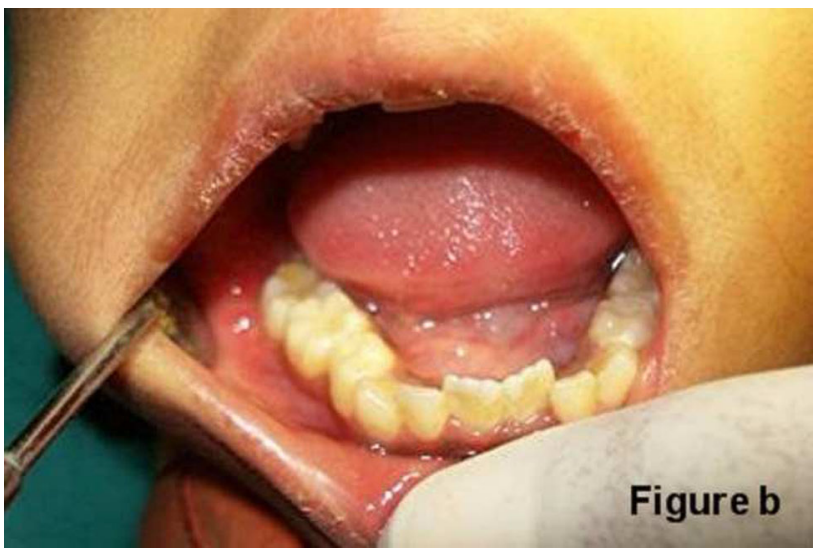

Fig. 2 Preoperative intraoral photograph showing expansion of buccal cortex

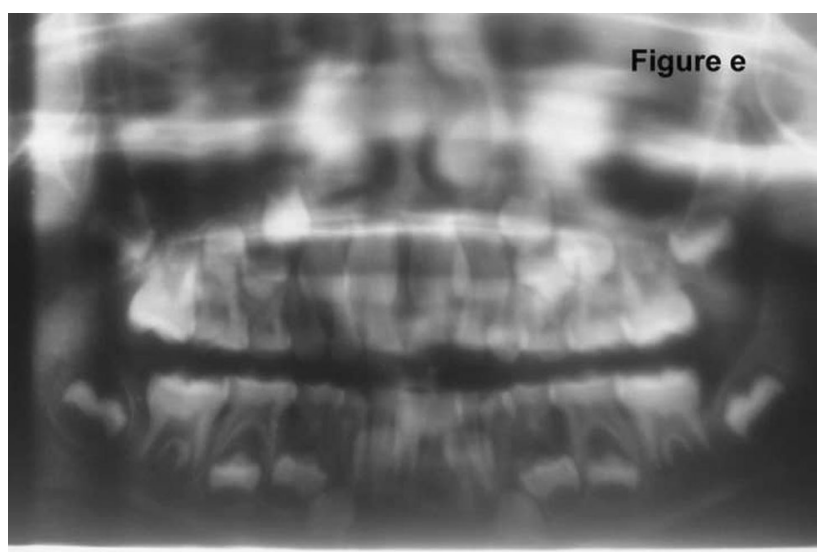

Fig. 3 OPG showing enlarged follicular space in 47

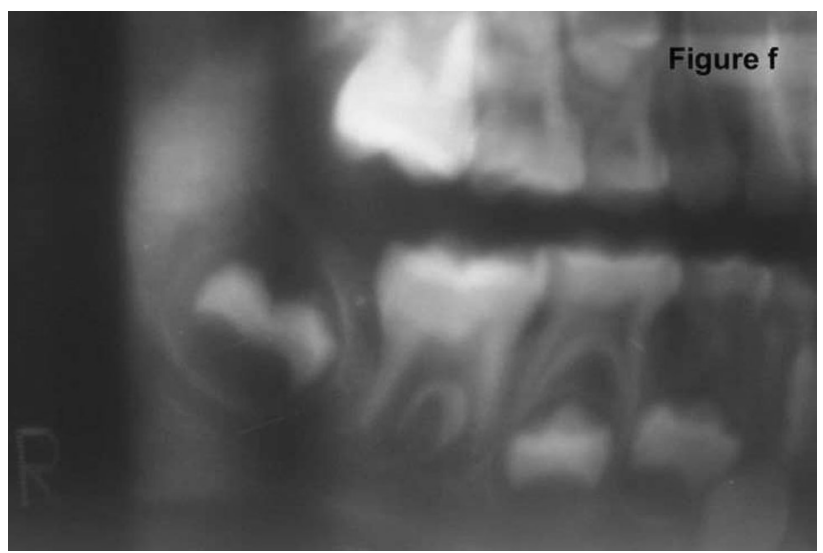

Fig. 4 Magnified view of right permanent second molar showing enlarged foliicular space

negative reports. The case was planned for enucleation under general anesthesia owing to the age of the patient.

Under GA following strict aseptic conditions, a full thickness mucoperiosteal flap was raised. Upon exposure 


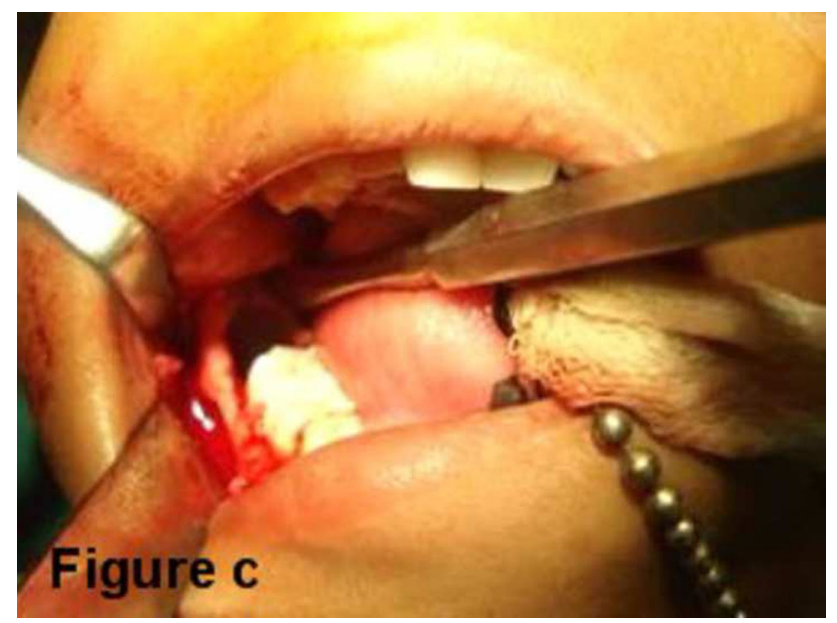

Fig. 5 Operative site during enucleation

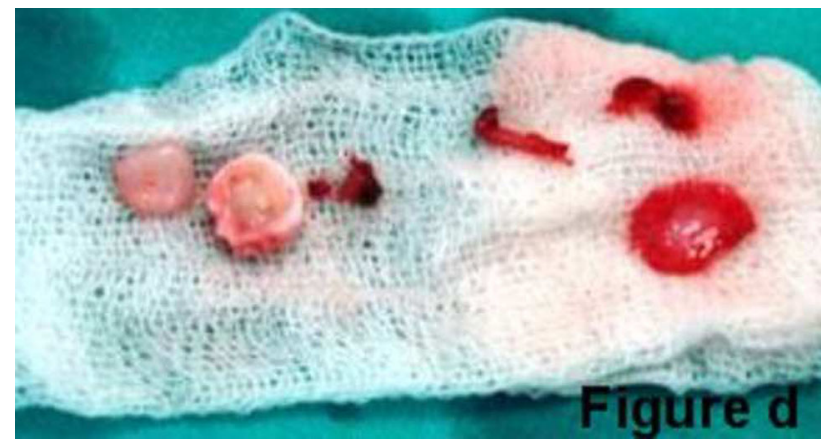

Fig. 6 Cyst enucleated along with offending tooth

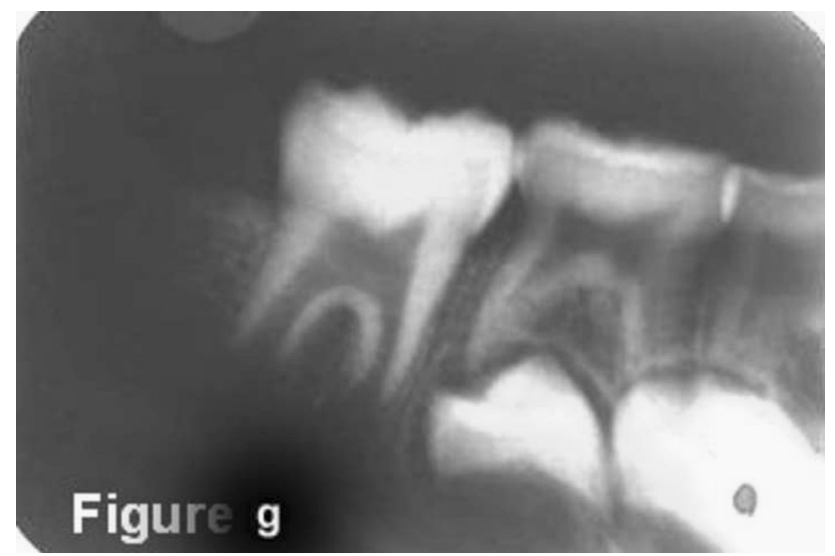

Fig. 7 Post operative radiograph

of the underlying buccal bone, it was noticed that there was a perforation of cortex on buccal side and pus was oozing out which might have been the reason for clinical appearance of the salty fluid in the mouth. The cyst was enucleated along with extraction of tooth bud of 47 (Fig. 5). Specimen (Fig. 6) was sent for histopathological examination. The flaps were placed in its original position and sutured.
The patient was discharged the next day without any complications. The patient was recalled after 7 days and sutures were removed and the wound healed uneventfully.

Histopathological report confirmed the lesion to be dentigerous cyst with follicle. Three months after the procedure, clinically the swelling had regressed in size and also IOPA showed no recurrence of the dentigerous cyst (Fig. 7).

\section{Discussion}

(a) The diagnosis of a dentigerous cyst is to be suspected clinically and radiographically before it is confirmed histologically. Radiographically, for a cyst to be considered as a dentigerous cyst, either the associated tooth should be an impacted one and/or the radiolucent space surrounding the tooth crown should be at least $5 \mathrm{~mm}$ in diameter $[13,14]$. Whereas in the present case the follicular size was merely $2 \mathrm{~mm}$ larger than the normal follicle.

(b) Though most of the times, the dentigerous cyst is associated with impacted third molars or canines, or some permanent teeth like central incisor, yet the occurence of such a cyst with permanent second molar is still uncommon and is about $1.1 \%$ [15].

(c) The occurence of such a cyst in second permanent molar not associated with nonvital tooth is unusual and rare.

(d) The commonly suggested pathogenesis of dentigerous cyst is mainly "developmental", that is formed by (i) accumulation of fluid between the reduced enamel epithelium and the enamel or within the enamel organ itself and (ii) eruption of the crown of the permanent tooth into a radicular cyst of its deciduous predecessor.

A variation to this concept is occurrence of an "inflammatory" etiology [15] which states that the inflammation at the apex of a deciduous tooth may lead to the development of an inflammatory follicular cyst. In the present case, the likelihood of inflammatory pathogenesis is more though the reason may be different since there is no deciduous predecessor for a second permanent molar. Also the adjacent permanent molar was non-carious and free from apical inflammation. Hence, the cause for formation of the dentigerous cyst around permanent second molar, in this case, could be the recurrent pericoronal inflammation (pericoronitis) that might have occurred at the time of eruption of permanent first molar [7].

It is known that dentigerous cysts may present with complications like pathologic fractures, transformation into true neoplasm (odontogenic keratocyst, ameloblastoma etc.) $[16,17]$. 
Malignant transformation is less common than ameloblastic transformation. The malignancy most commonly associated is squamous cell carcinoma though mucoepidermoid carcinoma is also possible [17].

In order to avoid such complications the following treatment protocol is described:

1. Total enucleation for small lesions $[1,18]$ and marsupialization for decompression of large volume cysts; or

2. a combination of both [19-21].

In our case treatment was performed using the enucleation technique.

Enucleation is the choice of treatment for small size lesions [22, 23]. It has been used successfully for dentigerous cysts. Prognosis is excellent, with no recurrence expected since pathological lining is removed completely [24].

Marsupialization or decompression is a technique that attempts to relieve intracystic pressure through the creation of an accessory cavity. This technique is a more conservative intervention for the treatment of large cysts, especially in paediatric dentistry. After marsupialization, a removable space-maintaining appliance is to be used, which permits decompression and prevents the entry of food into the cystic pouch. Cooperation of the parents is fundamental for treatment success. It is important to emphasize that the use of the marsupialization technique for treating cysts involving developing buds requires follow-up until the permanent teeth erupt. Also frequent inspection of the cystic cavity is required to rule out transformation to neoplasms.

In our case the (i) second molar was not a favourable site for retention of surgical stent, (ii) long follow-up was not possible owing to non-compliance on part of patient, (iii) moreover the cyst was expanding on the buccal side and perforating the buccal cortex suggesting a more aggressive nature as compared to its size, (iv) second molar was unlikely to erupt early owing to the fact that the root formation was in the initial stages.

Hence we preferred enucleation as a treatment option for this particular case.

Hence, it is suggested, that the choice of therapeutic approach for a dentigerous cyst should not be randomly selected but customized to patients' need, based on: the size and location of the cyst, patients' age, affected dentition, status of root completion of the associated tooth, clinical course, histological presentation [25], relationship with the surrounding structure and patients' compliance for a particular treatment.

\section{References}

1. Neville BW (2005) Oral and maxillofacial pathology, 2nd edn. Saunders, Philadelphia
2. Peterson LJ, Eliis E, Hupp JR, Tucker MR (2003) Contemporary oral and maxillofacial surgery, 4th edn. Mosby, St. Louis

3. Kushukakawa J, Irie K, Morimatsu M (1992) Dentigerous cyst associated with deciduous tooth: a case report. Oral Surg Oral Med Oral Pathol 73:415-418

4. Boyczuk MP, Berger JR, Lazow SK (1995) Identifying a deciduous dentigerous cyst. J Am Dent Assoc 126:832

5. Sands TC (1998) Multiple dentigerous cysts in a child. Oral Health $88: 27-29$

6. Ustuner E, Fitoz S, Atasoy C, Erden I, Akyar S (2003) Bilateral maxillary dentigerous cysts: a case report. Oral Surg Oral Med Oral Pathol Oral Radiol Endod 95:632-635

7. Benn A, Altini M (1996) Dentigerous cysts of inflammatory origin: a clinicopathologic study. Oral Surg Oral Radiol Endod 81:203-209

8. Arotiba JT, Lawoyin JO, Obiechina AE (1998) Pattern of occurrence of odontogenic cysts in Nigerians. East Afr Med J 75:664-666

9. Ziccardi VB, Eggleston TI, Schneider RE (1997) Using fenestration technique to treat a large dentigerous cyst. J Am Dent Assoc 128:201-205

10. Daley TD, Wysocki GP (1995) The small dentigerous cyst: a diagnostic dilemma. Oral Surg Oral Med Oral Pathol Oral Radiol Endod 79:77-81

11. Bodner L, Woldenberg Y, Bar-Ziv J (2003) Radiographic features of large cysts lesions of the jaws in children. Pediatr Radiol 33:3-6

12. Wood NK, Kuc IM (1997) Pericoronal radiolucencies. In: Wood NK, Goaz PW (ed) Differential diagnosis of oral and maxillofacial lesions. 5th edn. Mosby, St. Louis, pp 279-95

13. Goaz PW, Stuart CW (1994) Cysts of the jaws. In: Oral radiology, principles and interpretation, 3rd edn. Mosby, St. Louis, p 400

14. Gondim JO, Neto JJ, Nogueira RL, Giro EM (2008) Conservative management of a dentigerous cyst secondary to primary tooth trauma. Dent Traumatol 24:676-679

15. Shear M (2006) Cysts of the oral and maxillofacial region, 4th edn. Blackwell, Johannesburg

16. Mc Millian MD, Smillie AC (1981) Ameloblastomas associated with dentigerous cysts. Oral Surg Oral Med Oral Pathol. 51:489-496

17. Johnson LM, Sapp JP, Mcintire DN (1994) Squamous cell carcinoma arising from a dentigerous cyst. J Oral Maxillofac Surg 52:987-990

18. Desai RS, Vanaki SS, Puranik RS, Tegginamani AS (2005) Dentigerous cyst associated with permanent central incisor. A rare entity. J Indian Soc Pedod Prev Dent 23:49-50

19. Delbem AC, Cunha RF, Vieira AE, Pugliesi DM (2003) Conservative treatment of radicular cyst in a 5-year-old child: a case report. Int J Paediatr Dent 13:447-450

20. Perez DM, Molare MV (1996) Conservative treatment of dentigerous cysts in children. A report of 4 cases. J Indian Soc Pedod Prev Dent 14:49-51

21. Fortin T, Coudert JL, Francois B, Huet A, Niogret F, Jourlin M et al (1997) Marsupialization of dentigerous cyst associated with foreign body using 3D CT images: a case report. J Clin Pediatr Dent 22:29-33

22. Singh S, Singh M, Chhabra N, Nagar Y (2001) Dentigerous cyst: a case report. J Indian Soc Pedod Prev Dent 19:123-126

23. Carlos A, Delbem B, Frederico R, Rebeca C, Afonso L, Gerhardt K, Bianco Ana Paula I (2006) Dentigerous cysts in primary dentition: report of 2 cases. Pediatr Dent 28:269-272

24. Clauser C, Zuccati G, Barone R, Villano A (1994) Simplified surgical-orthodontic treatment of a dentigerous cyst. J Clin Orthod 28:103-106

25. Motamedi MH, Talesh KT (2005) Management of extensive dentigerous cyst. Br Dent J 198:203-206 